УДК 37.013

\title{
ПРОБЛЕМЫ СОЦИАЛИЗАЦИИ ПОДРОСТКОВ \\ И ВОСПИТАТЕЛЬНАЯ РОЛЬ БИОГРАФИЧЕСКОГО МЕТОДА \\ В СОВРЕМЕННОМ ОБРАЗОВАТЕЛЬНОМ ПРОСТРАНСТВЕ
}

\author{
Петряева Татьяна Андреевна \\ ФГБОУ ВО «Воронежский государственный \\ лесотехнический университет \\ им. Г.Ф. Морозова»
}

Аннотация: Статья посвящена своеобразию протекания подросткового возраста в контексте изменчивого современного общества последних десятилетий. Рассматриваются основные характеристики и социальные риски современных подростков - «бисерное сознание», опасности виртуального общения, размытые представления о гендерных границах и т.д. Обсуждаются способы и педагогические методы по воспитанию нравственных ценностей, формированию мировоззрения.

Ключевые слова: подростковый возраст, кризис идентичности, социализация, мировоззрение, биографии известных людей.

\section{PROBLEMS OF SOCIALIZATION OF ADOLESCENTS AND THE CORRECTIVE ROLE OF THE BIOGRAPHICAL METHOD IN THE MODERN EDUCATIONAL SPACE}

\section{Petryaeva Tatyana Andreevna}

\begin{abstract}
The article is devoted to the peculiarity of the course of adolescence in the context of the changing modern society of recent decades. The main characteristics and social risks of modern adolescents are considered - "beaded consciousness", the dangers of virtual communication, blurred ideas about gender boundaries, etc. Methods and pedagogical methods for the education of moral values, the formation of a worldview are discussed.

Key words: teenage years, identity crisis, socialization, worldview, biographies of famous people.
\end{abstract}




\section{НАУКА, ОБЩЕСТВО, КУЛЬТУРА: ПРОБЛЕМЫ И ПЕРСПЕКТИВЫ

Подростковый возраст - один из самых волнительных и значимых периодов в жизни человека. Несмотря на краткосрочность данного этапа в развитии личности его значение трудно переоценить. Непосредственно в это время происходят значительные изменения на телесном и психологическом уровнях: подросток переживает гормональные изменения, стремится стать частью взрослой жизни, учится нести ответственность за свои поступки и решения, но, что еще важнее, - идет поиск своей ниши в социуме. В этот период человек начинает осознавать свое «Я», осуществлять поиск смысла жизни, нравственных ориентиров и ценностей, которые в дальнейшем станут базой для формирования своего личного мировоззрения, отношения не только к окружающему миру, но и самому себе.

Феномен подросткового возраста, как один из значимых этапов становления личности, уже много лет привлекает внимание научных исследователей. Наиболее глубоко данный возрастной период стал изучаться в контексте педагогики, психологии и социологии после Первой мировой войны. Сегодня большинство ученых приходит к выводу, что подростковый возраст охватывает время жизни человека с 11 до 14-15 лет, совпадая в целом с обучением детей в средних классах школы [1, с. 345]. Примерно о тех же возрастных рамках пишет и Эрик Эриксон в своей знаменитой работе «Идентичность: юность и кризис».

Вместе с тем, необходимо осознавать, что работа современных педагогов и психологов выстраивается на фундаментальных трудах, описывающих особенности развития подростка прошлых десятилетий. Однако вторжение в нашу жизнь персональных компьютеров, интернета, возможность общения с неограниченным числом людей в социальных сетях, доступность практически любой информации, внедрение искусственного интеллекта, в том числе в сфере образования, изменение образа жизни людей вследствие пандемии, - все это значительно изменяет протекание жизни и современных подростков, делает процесс их взросления и включения в социум еще более сложным и многовариантным. Поспеть за всеми этими стремительными преобразованиями, дать глубокую и фундаментальную оценку изменениям протекания подростковой жизни современным ученым в области педагогики, психологии и социологии очень сложно. Говорить о возможности появления каких-то новых серьезных научных трудов в этой сфере практически невозможно, поскольку еще сегодня актуальная информация уже завтра становится 
устаревшей и неприменимой в новых условиях. Поэтому особое значение приобретают наблюдения или размышления исследователей в научной периодике.

Так, например, в известном и уважаемом в научных кругах журнале «Тhe Lancet» приводятся данные о том, что рамки подросткового возраста порой продлеваются даже до 24 лет. Замедляется, указывается в исследовании, не только психологическое, а даже и биологическое взросление современного человека [2, с. 905]. По мнению социологов, этому способствует экономическое благополучие, а также смягчение социальных норм. Таким образом, сегодня мы имеем дело с совершенно другим подростком, чьи особенности мало изучены.

Все это ставит задачу пересмотреть отношение к пониманию таких понятий как «кризис подросткового возраста» и «кризис идентичности», которые, как представляется, должны пониматься как неизбежный поворотный пункт, критический момент, после которого развитие повернет в ту или иную сторону, используя возможности роста, мыслительной деятельности [3, с. 12].

Современный подросток не похож на подростка двадцатилетней давности. Конечно, взрослые люди в любую эпоху говорили и говорят, что «теперь молодежь другая», но сейчас имеются в виду характеристики, свойственные исключительно подростку 21-ого века, живущему в эпоху информационной революции. Поэтому, чтобы понимать их сущность и вовремя помогать ребенку на его жизненном пути, крайне важно знать эти особенности. Взрослые должны быть интересны подрастающему поколению, а для этого необходимо не догонять подростка, а идти в ногу с ним, а порой и в чем-то опережать.

Технологии, к которым сегодня есть доступ практически у каждого ребенка, еще вчера казались человеку недостижимыми, о них можно было узнать только из фантастических книг или фильмов. Современные подростки привыкли воспринимать потоки терабайтов хаотичной информации, для них это обязательная составляющая часть жизни, причем весьма значительная. Подросток просыпается, и первое, что он делает, тянется к своему смартфону, им начинается и им же завершается день. За сутки через современного подростка проходит многочисленное количество ярких впечатлений. Он листает ленты новостей, смотрит истории в Instagram, Tik-Tok, просматривает большое количество подкастов, следит за 
новостями по телевизору, слушает музыку в наушниках, когда едет в автобусе или идет по улице.

Во многом способность воспринимать большой поток разнообразной информации формирует навыки решения многозадачных ситуаций, где необходимо проявить не только знания, но и скорость реакции. Однако чаще всего в силу возраста и психического развития подростки не подвергают увиденное и услышанное критическому оцениванию, они еще не способны анализировать полученную ими информацию, принимая ее целиком, что называется, на веру, и тем самым нередко становясь объектом манипулирования. Многочисленные видео и аудио материалы, воспринимаемые без критического анализа, порождают феномен «сознания бисерного типа», когда подросток знает довольно много, но информация содержится в хаотичном и обесцененном виде.

Важной частью подростковой жизни являлись подростковые группы и компании сверстников. Общение со сверстниками для подростка является одним из самых важных и значимых видов деятельности. Между тем, теперь данный вид деятельности реализуется не через устойчивые школьные или дворовые компании, а путем виртуального общения, например, в тех же социальных сетях. По мнению известного психолога Кирилла Хломова, подобная среда, с одной стороны, позволяет ребенку развиваться в более комфортной среде, но, с другой, делает возможность общения в условиях реальной жизни более сложной и затрудненной. Современным подросткам стало намного труднее начать реальное общение, а также предположить возможные варианты его завершения, что необходимо для успешной социализации и полноценной жизни.

Явно поменялась и семейная среда, в которой воспитывается подросток. В современном обществе социальный институт семьи претерпевает ряд существенных преобразований: меняется отношение к семье, иногда даже можно услышать мнение об ее отмирании и ненужности, изменяется семейный состав, социальные роли родителей и супругов. Современное общество одобряет и предлагает довольно большое количество вариантов семейной жизни: семья с одним родителем, сложносочиненная семья, где подросток воспитывается сразу в нескольких семьях: мамы с отчимом, отца и мачехи, даже в семьях своих родственников, получая таким образом совершенно разный опыт родительских фигур. Такое многообразие, безусловно, тоже влияет на развитие подростка [4, с. 111]. 
Невероятно проблемной зоной для подростка является область сексуальной идентичности. Современный мир демонстрирует ему толерантное отношение не только к гендерным границам и равенству женщин с мужчинами, но и к сексуальной принадлежности. В настоящее время посредством мощнейшего воздействия СМИ, массовой культурной индустрии и моды людям демонстрируют и навязывают одежду без какихлибо половых признаков и особенностей. Порой только по внешним признакам совершенно невозможно определить, к какому полу относится подросток. Мнения о том, что в конечном итоге эта ситуация пагубно влияет на представления подростка о самом себе и мешает становлению у него адекватных социальных ролей и поведения, зачастую объявляются нетолерантными.

Как же повлиять на процесс социализации личности подростка? Какие технологии в той же образовательной среде использовать, чтобы минимизировать пагубное воздействие некоторых аспектов современного общества на подростка и не остановить его позитивного личностного развития? Что можно сделать в связи с этим в нынешнем образовательном пространстве? И вообще, возможно ли это? Конечно, надо быть реалистами: лишь отчасти. Тот новый «культурный» поток, с которым мы сегодня столкнулись, имеет беспрецедентную идеологическую и финансовую поддержку. И все же...

Очевидно, что коррекция идентичности подростка и реализация процесса его социализации возлагаются, прежде всего, на институт школы и учителя. Представляется, что современная школа должна сделать доминирующим вектором своей деятельности не столько достижение учащимися предметных результатов (эта задача стояла и стоит перед ней, что называется, a priori), сколько формирование в их сознании нравственных гуманистических основ. Ведь совершенно справедливо замечено мудрыми: «Сегодня - дети, завтра народ».

Думается, для достижения этой цели из многих других способов и методов воспитания максимально подходит использование в учебном процессе биографического метода, способствующего формированию навыков критического анализа социальной реальности. Проведенные автором исследования на базе общеобразовательных учреждений Санкт-Петербурга доказывают удивительную эффективность этого метода в формировании личности подростка. [5, с. 88]. 


\section{Список литературы}

1. Реан А. А. Психология человека от рождения до смерти / под ред. А.А. Реана. - СПб.: ПРАЙМЕВРОЗНАК, 2002. - 656 с.

2. Чумаков С. А. Особенности современного подросткового возраста // Электронный журнал «Центр Педагогического Сотрудничества». - 2018. №7(23).- С. 904-907.

3. Толстых А. В. Идентичность: юность и кризис / под ред. А.В. Толстых. - М.: Издательская группа «Прогресс» 1996. - 344 с.

4. Хломов К. Д. Социальные риски в контексте индивидуальных жизненных траекторий современных подростков // Социальная психология и общество. - 2016. - №2. С. 109-125.

5. Петряева Т. А. Влияние биографий известных людей на формирование нравственных установок у современных школьников // Актуальные вопросы современной науки и образования : сборник статей IV Международной научно-практической конференции, состоявшейся 15 февраля 2021 г. Петрозаводск. - с. 260.

(C) Т.А. Петряева, 2021 